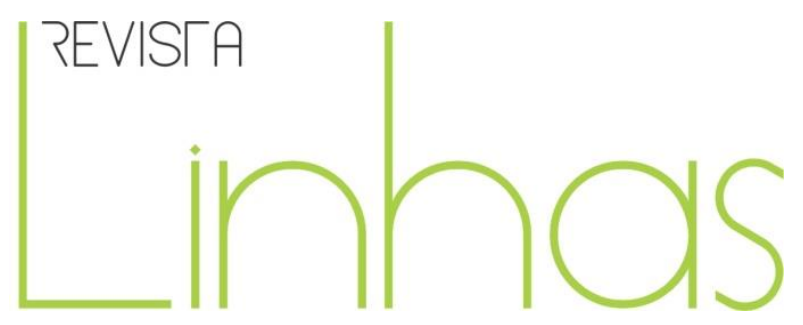

\title{
Pedagogia universitária: enfoques frente à formação de professores do ensino superior
}

\section{Resumo}

Este artigo visa abordar a pedagogia universitária e seus enfoques frente à formação dos professores do ensino superior, nos contextos sociais, históricos, culturais e tecnológicos, como essenciais à prática docente, voltada para a transformação social, para além do capital. No decorrer da história, as necessidades, aspirações e valores em torno do ensino superior tiveram mudanças significativas. Desse modo, o mesmo necessita de professores formados num processo continuado e permanente, caso contrário, ficarão lacunas numa educação que prima pela qualidade, para além dos limites do mercado. Direcionamo-nos ao ensino superior como uma possibilidade de desenvolvimento para a transformação social, sendo a universidade uma das instituições mais exigidas desde a formação de qualidade pelo ensino, até a resolução dos problemas sociais pela pesquisa e pela extensão. A proposta de pedagogia universitária encontra-se voltada à discussão sobre a possibilidade de construir desenhos curriculares que articulem diferentes campos de saberes. Nessa perspectiva, devem ser consideradas dimensões políticas, éticas, sociais e técnicas, estando articuladas com a formação profissional, na perspectiva de transcender a lógica tradicional de fragmentação de conteúdos. Esta compreensão volta-se para uma pedagogia universitária que visualiza uma universidade, professores, alunos, ensino, pesquisa e extensão para o século XXI. E que este professor reflita que deve trazer em sua prática pressupostos de uma pedagogia universitária, que possibilite refletir, analisar, comparar, criticar, justificar, argumentar e inferir, assumindo efetivamente o compromisso indissociável entre ensino, pesquisa e extensão.

Palavras-chave: Ensino Superior; Formação de Professores; Pedagogia Universitária.
Kelin Cristiani Feldhaus

Universidade do Planalto

Catarinense - UNIPLAC - SC/Brasil

kelincf@hotmail.com

\section{Geraldo Antônio da Rosa}

Universidade de Caxias do Sul UCS - RS/Brasil geraldorosa06@gmail.com

\footnotetext{
Para citar este artigo:

FELDHAUS, Kelin Cristiani; ROSA, Geraldo Antônio da. Pedagogia universitária: enfoques frente à formação de professores do ensino superior. Revista Linhas. Florianópolis, v. 17, n. 34, p. 242-265, maio/ago. 2016.
} 


\title{
University pedagogy: opposite approaches to teacher education upper
}

\begin{abstract}
This article aims to address the university pedagogy and their approaches across the training of higher education teachers, social, historical, cultural and technological contexts as essential teaching practice, focused on social transformation, beyond the capital. Throughout history the needs, aspirations and values around higher education have undergone significant changes. Thus, the same need teachers trained in a continuous and ongoing process, otherwise it will be gaps in education that excels in quality beyond the market boundaries. We headed to higher education as a possibility of development for social transformation, and the university one of the required institutions since the formation of quality in teaching, until the resolution of social problems by research and extension. The proposed university pedagogy is focused the discussion on the possibility of constructing curricular designs that combine different fields of knowledge. In this perspective should be considered political, ethical, social and technical dimensions, being articulated with vocational training with a view to transcend the traditional logic of content fragmentation. This understanding turns to a university pedagogy that displays a university, teachers, students, teaching, research and extension to the twenty-first century. And this professor thinks that should bring in their practice assumptions of a university pedagogy that enables reflect, analyze, compare, criticize, justify, argue and infer, effectively taking the inseparable commitment of teaching, research and extension.
\end{abstract}

Keywords: Higher Education; Teacher Training; Pedagogy University. 


\section{Introdução}

A docência no ensino superior evoca características diferenciadas, ressaltando o contexto, desta forma enaltecendo uma ação docente também diferenciada da tradicionalmente praticada, conforme citam Pimenta e Almeida (2011), quando falam de um professor universitário capaz de atuar de forma reflexiva, crítica e competente no âmbito de sua disciplina, dando sentido e significado, além da sua contribuição no percurso formativo dos estudantes. Queremos tratar de educação e da construção de um espaço de transformação social, para além do capital, isso requer considerar a história da Educação e como ela vem sendo compreendida na contemporaneidade.

Para melhor compreensão e fundamentação teórica, temos como base as obras de SAVIANI, A pedagogia no Brasil - História e teoria, 2008; SAVIANI, Pedagogia HistóricoCrítica primeiras aproximações, 1995; SAVIANI, História das Idéias Pedagógicas no Brasil, 2008; CAMBI, História da Pedagogia, 1999, tratando do histórico da pedagogia. No que concerne à fundamentação diante da interdisciplinaridade e compartilhamento de saberes, nossa base teórica será SANTOMÉ, Globalização e Interdisciplinaridade; o currículo integrado, 1998. Diante das abordagens sobre o professor universitário, utilizamos: MOROSINI, Professor do ensino superior; identidade, docência e formação, 2001; ZABALZA, O ensino universitário: seu cenário e seus protagonistas, 2004, Garrido Pimenta: Docência no ensino superior, 2003; Pedagogia Universitária - caminhos para a formação de professores, 2011; Pedagogia: ciência da educação?, 2011. Sobre educação, nos fundamentamos em DEMO, Cidadania tutelada e cidadania assistida, 1999. No que concerne ao estudo sobre a pedagogia universitária, nos fundamentamos em FERNANDES E GRILLO, Educação Superior travessuras e atravessamentos, 2001; MAZZETTO, Competências Pedagógicas do Professor Universitário, 2003; PIMENTA e ALMEIDA, Pedagogia Universitária - caminhos para a formação de professores, 2011; PIMENTA, Docência no ensino superior, 2003.

Ao longo da história, o tema educação aguçou discussões que originaram novos direcionamentos e significados no contexto da Educação, sendo fruto das contradições sociais, humanas e culturais. A história da Educação é hoje, segundo Cambi (1999, p. 29), "um repositório de muitas histórias dialeticamente interligadas e interagentes", reunidas pelo objeto complexo 'educação'. Diante do pensamento de Cambi, salientamos que a 
Educação é parte integrante do social e que este social é composto de diferentes culturas, de diferentes sujeitos, que numa perspectiva histórico-crítica precisa ser instrumento de transformação social na busca da produção de conhecimento, transcendente para além do capital.

Neste sentido, Brandão (2001) considera que o alicerce da educação é construído com base no contexto social, histórico, cultural, não devendo ser tratado de forma imposta e definido fora do seu contexto. O mesmo autor traz o exemplo da situação de proposta dos governantes dos Estados Unidos, em Virgínia e Maryland, de uma alternativa de educação a ser aplicada junto aos índios, na tentativa de um tratado de paz, convidando jovens índios a estudarem em escolas dos brancos, mas receberam dos índios tal resposta:

Nós estamos convencidos, portanto que os senhores desejam o bem para nós e agradecemos de todo coração. Mas aqueles que são sábios reconhecem que diferentes nações têm concepções diferentes das coisas e, sendo assim, os senhores não ficarão ofendidos ao saber que a vossa ideia de educação não é a mesma que a nossa. (BRANDÃO, 2011, p. 8)

Propostas desta origem continuam sendo práticas comuns, como no caso da elaboração de leis, de programas elaborados sem considerar o real contexto social, histórico, cultural e tecnológico onde serão aplicadas as propostas, desconsiderando o caráter de transformação social, mas reforçando o desenvolvimento para a produção de capital e não de conhecimento. A fala de Brandão (2001) reforça que, desde outros momentos históricos, a educação já era tratada fora de uma premissa de superação do capital, mas ainda de reforço das ideologias dominantes. Cabe aqui destacar que importante é considerar que não há um único modelo de educação, nem um único lugar: o ensino escolar não é o único, nem o professor seu único praticante.

Falar em educação necessariamente instiga considerar a formação de professores e, direcionando à nossa investigação, especificamente para o ensino superior. Pimenta (2003, p. 37) traz uma reflexão de que "a docência na universidade ultrapassa os processos de sala de aula". Contudo, pensemos se este professor está preparado para ultrapassar os processos da sala de aula. Será que sua formação o possibilita 
compreender as relações dos contextos sociais, culturais, tecnológicos e conhecimentos teóricos desenvolvidos em sala de aula? A mesma autora destaca que os professores do ensino superior recebem ementas prontas, planejam individualmente e se responsabilizam pela docência exercida: "Não recebem qualquer orientação sobre os processos de planejamento, metodológicos ou avaliatórios, não têm que prestar contas, fazer relatórios, como acontece normalmente nos processos de pesquisa".

A escrita de Pimenta (2003) data do século XXI, mas traz a formação de professor enraizada em princípios muito antes definidos, externando uma formação pautada em dar aulas, em saber tecnicamente o conteúdo e simplesmente trabalhá-lo, sem ter a preocupação de superar, de desenvolver para a transformação, para o pensar, para a contradição. Diante de tudo isso, é necessário estudar uma metodologia diferenciada de ensino.

Para compreender este contexto de transformação social, "historiaremos" o conceito de Pedagogia no Brasil, no que se refere às diferentes significações atribuídas no decorrer da história, analisando desta forma as interpretações que se têm da educação.

\section{Sobre a Pedagogia: da análise à crítica}

É na Grécia que começa a História da Educação. São os gregos que, pela primeira vez, colocam a educação como problema. Já na literatura grega se veem sinais de questionamento do conceito, seja na poesia, na tragédia ou na comédia. É então que o ideal educativo grego aparece como Paideia, formação geral que tem por tarefa construir o homem como homem e como cidadão. Para aprofundarmos nossa conversa sobre educação, optamos por resgatar a história da Pedagogia sob a luz de Cambi (1999) e Saviani (2008).

Se, para Brandão (2001), a educação está relacionada ao contexto, a história, o social, a política, a cultura e, ainda, segundo Cambi (1999, p. 21), a história da Pedagogia ampliou-se para a história da Educação, isso demonstra que a educação é vista hoje mais do que a pedagogia trazida por Cambi (1999) como "empenhada na organização de uma instituição cada vez mais central na sociedade moderna (para formar técnicos e para 
formar cidadãos), preocupada, portanto, em sublimar os aspectos mais atuais da educação-instrução", mas suponhamos que uma pedagogia voltada para a transformação social.

Partindo do reconhecimento de que a complexidade que envolve o tema Educação deriva do fato de que nela interferem diversos fatores e que compreendê-la implica levar em conta diversas perspectivas, Saviani (2008) observa que há um termo comum entre os diversos enfoques no que se refere ao conceito de Pedagogia: ciência da Educação, arte de educar, técnica de educar, filosofia da Educação, história da Educação... Todos fazem referência explícita à “Educação”, tornando-a ponto de partida, construído a partir e, em função da realidade. Faz-se necessário um adendo; frente a qual realidade estamos falando: uma realidade de contradições sociais, culturais e políticas, ou uma realidade definida e alinhada conforme as premissas dos dominantes? Outra indagação seria sobre o próprio conceito de Pedagogia trazido por Saviani: arte de educar o quê e a quem?

E no século XXI, este processo continua ocorrendo? Quais tentativas diferenciadas de ensino identificam-se como bem sucedidas, tratando da ideia de formar cidadãos para compreender, julgar e intervir na sociedade, na compreensão dos nexos que permitem sua estruturação com base na realidade?

Santomé (1998, p. 25) destaca que os currículos podem ser organizados de diferentes formas, não somente em torno de disciplinas, mas ultrapassando os limites das disciplinas, centrados em tema, problemas, instituições, períodos históricos, espaços geográficos: "trata-se de cursos nos quais os alunos seriam obrigados a manejar referenciais teóricos, conceitos, procedimentos, habilidades de diferentes disciplinas, para compreender ou solucionar as questões e problemas propostos".

Fazendo um recorte ainda mais distante, na segunda metade do século $X X$, o que representa um período de aproximadamente 60 anos somente, fundamentamos os porquês de tantas mudanças e redimensionamentos. De acordo com Cambi (1999), a Pedagogia passou por uma transformação, renovando seus limites e deslocando seu eixo epistemológico, sendo este um caminho sem volta, tendo em vista todas as transformações históricas - como podemos citar, no Brasil, a Revolução de 1964, diante da tomada do governo pelos militares. Mundialmente falando, podemos citar a 
necessidade de reconstrução da Europa pós-guerra, o fim da União Soviética, ocasionando a abertura do mercado, e ainda a Guerra Fria; completamos com o advento da globalização, exigindo relações mais complexas, que demandavam dos sujeitos que, além de saber desempenhar tecnicamente suas funções, também fossem capazes de buscar inovações no social e no que se referia à cultura, conforme descreve Cambi:

o advento de uma sociedade cada vez mais dinâmica e mais aberta, que reclama a formação de homens sensivelmente novos em relação ao passado; homens-técnicos e homens-abertos capazes de fazer frente às inovações sociais, culturais e técnicas. Para realizar a formação desses homens é necessário um novo fazer pedagógico, mais experimental, mais empírico, mais problemático e aberto à própria evolução. (CAMBI, 1999, p. 595-596)

O foco da Pedagogia, segundo Cambi (1999), para a formação deste homem era um fazer mais empírico, voltado à experimentação, trabalhando com problemáticas oriundas do contexto, estabelecendo relação com a formação de um homem-técnico, mas aberto às inovações.

Desta forma, a Pedagogia de um saber unitário e "fechado", conforme já citamos em Cambi, passa à ciência da Educação, um saber plural e aberto, tratando de uma renovação no saber educativo. Ainda segundo Cambi (1999), esta passagem é um caminho sem volta, pois hoje é impossível pensar os problemas educativos de forma tradicional, ligada a um saber pragmático.

No decorrer da história, as necessidades, aspirações e valores em torno da Educação tiveram mudanças significativas, acompanhando os avanços e transformações ocorridos no contexto histórico e social. Desse modo, a Educação é considerada um ato social e político e, portanto, conforme Mèszáros (2005), um processo continuado, permanente; caso contrário, não atende aos requisitos esperados de uma educação com qualidade.

Ao abordar a educação como um processo continuado para atender aos requisitos de uma educação de qualidade, compreendida como aquela voltada para transcender a lógica do capital, voltada à transformação social, para a criação de ideias, direcionamo- 
nos ao ensino superior como uma possibilidade de desenvolvimento para a transformação social. Conforme Fernandes e Grillo (2001, p. 41), "a universidade tem sido, talvez uma das instituições mais exigidas desde a formação de qualidade até a resolução dos problemas sociais pela pesquisa e pela extensão". Sendo assim, trazemos à tona algumas questões diretamente relacionadas à formação do professor do ensino superior, como sua relação com a pesquisa, com os contextos, com as pessoas.

Mazzetto (2003) reitera esta preocupação com a formação do professor, tratando o ensino desta fase como

[...] uma preocupação total e exclusivamente voltada para a transmissão de informações e experiências, iniciou-se um processo de buscar o desenvolvimento da aprendizagem dos alunos; de aperfeiçoar sua capacidade de pensar; de dar significado para aquilo que era estudado, de perceber a relação entre o que o professor tratava em aula e sua atividade profissional; de desenvolver a capacidade de construir seu próprio conhecimento, desde coletar informações até a produção de um texto que revele seus conhecimentos. (MAZZETTO, 2003, p. 19-20)

Nota-se que trabalhar a formação do professor está intimamente ligado à pesquisa, uma vez que, para buscar a práxis pedagógica, requer-se reconhecer contextos, e isso só ocorre através da pesquisa. Podemos aqui citar Pimenta (2011, p. 7), quando trata da docência universitária e faz menção à atuação do docente do ensino superior, pois é responsável pelo "preparo de todos os tipos de profissionais que necessitam de formação especializada". Salienta ainda que

[...] formar profissionais competentes e sintonizados com as demandas do mundo atual, que tenham senso de justiça social e uma identidade profunda com a cidadania democrática, é tarefa que exige muito mais desses professores do que repassar os conteúdos de sua área de especialização stricto sensu. (PIMENTA, 2011, p. 7)

Acerca desse contexto, Demo (1990, p. 37) aborda a pesquisa como "diálogo inteligente com a realidade" tomando-o como atitude integrante do processo cotidiano. Salienta ainda a necessidade deste diálogo não ser algo solene, mas uma necessidade de 
comunicação entre professor e aluno, não como expressão de consenso, mas também de confronto, não copiando, mas reconstruindo, ressignificando a realidade.

Mazzetto (2012, p. 23-24) em sua obra Competência pedagógica do professor universitário (2012) fala da docência universitária como profissionalismo e apresenta quatro situações perceptíveis diante das mudanças no ensino superior e na docência universitária:

- "No processo de ensino", destacando o significado do que é estudado, a capacidade de pensar, a relação entre aula e atividade profissional, a construção de conhecimento, promovendo o desenvolvimento de um cidadão responsável, responsável com a desenvolvimento de sua comunidade.

- "No incentivo à pesquisa", não bastando apenas formar profissionais técnicos e divulgadores de pesquisas realizadas fora do país, mas pesquisadores produzindo conhecimento sobre problemas reais e concretos. Para isso, os professores precisam trazer questões de cidadania para dentro das universidades.

- “Na parceria e coparticipação entre professor e aluno no processo de aprendizagem”. Embora Masetto ainda perceba essa parceria de forma iniciante, sinaliza ações de professores do ensino superior com atitudes mais abrangente do processo de aprendizagem com ênfase ao aprendiz como sujeito do processo, repercutindo em ações na sociedade, acerca da extensão.

- "No perfil docente". O autor chama a atenção que o professor passa de especialista para mediador de aprendizagem. Isso não significa que exige menos do mesmo quanto ao domínio da área em que leciona, mas exige dele pesquisa e produção de conhecimento. No que concerne à extensão, o foco é a transformação das realidades reais, conectadas à universidade.

Após este breve histórico da Pedagogia e processo de formação dos professores para o ensino superior e o devido destaque da relevância deste profissional para a sociedade contemporânea, conforme cita Pimenta (2011, p. 8), percebe-se uma necessidade de rever as atuações e reavaliar práticas pedagógicas no ensino superior, apontando, de acordo com a autora, para "superar os discursos que a consideram fruto 
de uma mera vocação ou da transposição das atuações exitosas realizadas no campo de atuação profissional". É preciso encontrar uma forma de redirecionar este discurso e tornar uma ação pedagógica voltada para o pensar, para a crítica, para a superação da lógica do capital e contemplar o ensino, a pesquisa e a extensão. Um meio que se propõe é a pedagogia universitária que valorize a reflexão, a contradição e a produção de ideias.

\section{Pedagogia universitária e algumas características}

Trabalhar na perspectiva de produção de ideias exige profissionais alinhados a uma pedagogia universitária, ou seja, uma forma de trabalho que pressupõe professores capazes de considerar os contextos histórico, social, cultural e organizacional de onde realizam suas práticas. Segundo Pimenta (2011, p. 28), a mediação da prática coloca-se como "indispensável, porém, em estreita articulação com a teoria e ancorada na reflexão, enquanto processo que busca atribuir sentido àquilo que se pratica". Esta proposta

implica em novas ações por parte dos professores, num processo de formação continuada; configura novos modos de planejar atividades a serem desenvolvidas pelos alunos de forma autônoma, uma nova organização de recursos e espaços. Apresentar novas propostas é uma forma de enfrentar a modernidade; no entanto, envolve pessoas, profissionais que tiveram sua formação desalinhada à contemporaneidade e que por diversos motivos, já citados, precisarão rever suas práticas e renovar formas de exercer a pedagogia universitária.

Muito se percebe que a docência universitária vai se construindo individualmente, por tentativas e erros, tendo como base professores já observados ao longo da própria formação, e "este modo de se construir docente não facilita avanços significativos, dificultando a construção de inovações na prática pedagógica", conforme Pimenta (2011, p. 81).

Mazzetto (2003, p. 24) traz uma contribuição importante diante da formação do professor quanto ao domínio de determinada área do conhecimento, destacando que isso não significa exigir menos do professor, mas ao contrário, exige-se dele pesquisa e produção de conhecimento, além de atualização e especialização para que possa incentivar os alunos a pesquisar. Destaca ainda que o professor que não pesquisa, não 
consegue incentivar os alunos a pesquisar, além de que o cenário do ensino coloca o aprendiz, como sendo professor e aluno, no centro, "em que professor e aluno se tornam parceiros e coparticipantes do mesmo processo".

Ao encontro da fala de Mazzetto (2003) frente ao incentivo à pesquisa, Pimenta (2011) traz uma questão relevante que é de que a produção de conhecimento necessita partir da problematização dos conhecimentos historicamente produzidos, trazendo resultados na construção da sociedade e das novas demandas que esta se coloca, destacando a necessidade de

[...] políticas para essa formação devam ser enraizadas nos contextos sociais, econômicos e culturais que envolvam e afetem a trajetória da universidade contemporânea [...] completa que [...] a universidade é uma instituição educativa cuja finalidade é o permanente exercício da crítica, que se fundamenta na pesquisa, no ensino e na extensão.(PIMENTA, 2011, p. 21)

Numa análise simplificada, julga-se coerente esta nova cultura, no entanto, pensemos como deveria ser a organização da carga horária deste professor, para o exercício desta nova cultura acadêmica, voltada ao contexto? Pimenta (2011, p. 22) salienta que é na contramão destas “disciplinas dispostas em gôndolas, à escolha do estudante, e disponibilizadas conforme a decisão individual dos docentes ou departamentos" que precisamos caminhar, criando, desta forma, uma

[...] nova cultura acadêmica nos cursos de graduação, que considere o direito ao acesso a uma formação que garanta aos estudantes o desenvolvimento de uma postura frente ao saber, que supere a especialização estreita, problematize as informações e garanta a sua formação como cidadão e profissional cientista compromissado com a aplicação de conhecimento em prol da melhoria da qualidade de vida de toda a sociedade; que possibilite o pensamento autônomo; [...] desenvolva metodologias de busca e de construção de conhecimento; [...] mobilize visões inter e transdisciplinares, [...] enfim, uma nova cultura acadêmica que valorize o trabalho dos docentes na graduação. (PIMENTA, 2011, p. 23) 
A proposta de construção de uma nova cultura acadêmica no que se refere à pedagogia universitária requer, segundo Pimenta (2011), incentivar a discussão sobre a possibilidade de construir desenhos curriculares que articulem diferentes campos de saber, considerando dimensões políticas, éticas e técnicas, articuladas com a formação profissional, na perspectiva de transcender a lógica tradicional de fragmentação de conteúdos. Pimenta (2011) salienta que estruturar currículos globalizantes é um desafio. Estes currículos globalizantes são compreendidos por Zabalza (2004) como aqueles que se organizam por situações, temas ou ações, independentes da existência de uma disciplina a ser trabalhada. Mas esta ação exige novo modo do professor do ensino superior de organizar seu trabalho. Para enriquecer a discussão diante da pedagogia universitária, Mazzetto (2003, p. 29) reforça que “precisamos de um professor com papel de orientador das atividades que permitirão ao aluno aprender, que seja um elemento motivador e incentivador de desenvolvimento dos alunos, que esteja atento para mostrar o progresso deles, bem como corrigi-los quando for necessário".

Fernandes e Grillo (2001, p. 139) completam a discussão sobre a formação e atitudes dos professores do ensino superior e também no que condiz à pedagogia universitária, destacando que o professor do ensino superior "precisa rever os paradigmas do processo ensino-aprendizagem, redimensionando o conceito de ensinar e de aprender". Desta forma compreendendo o termo aprender, "como a buscar informações, rever a própria experiência, adquirir habilidades, adaptar-se as mudanças, descobrir significados nos seres, nos fatos, nos fenômenos e nos acontecimentos, modificar atitudes e comportamentos".

Esta compreensão é divergente de instruir, mostrar, guiar, comunicar conhecimentos, mas sim, segundo Fernandes e Grillo (2001, p. 139) quando o professor do ensino superior "reflete, analisa, compara, critica, justifica, argumenta, infere." Desta forma, discutir a formação de professores, na perspectiva histórico-crítica, requer compreender que a formação de professores é uma ação contínua e progressiva; em nenhum momento assume-se a visão dicotômica da relação teoria-prática. O processo de formação é contextualizado histórica e socialmente e, sem dúvida, constitui-se um ato político, pois é uma reflexão conjunta, na medida em que a prática decorrente dessa formação será necessariamente coletivizada. Não é uma construção isenta de conflito, 
mas torna-se mais produtiva se e quando partilhada, e a formação como processo significa uma articulação entre formação pessoal e profissional, construindo caminhos para a formação de docentes universitários.

Na sua obra Educação no século XXI - os desafios do futuro imediato Imbernóm (2000) apresenta cinco tendências principais acerca da educação do século XXI. A primeira refere-se às "mudanças socioemocionais" com o surgimento da sociedade de informação. A segunda aborda as mudanças constantes nos "níveis socioculturais". A terceira tendência trata de uma "cultura educativa que transforme". A quarta reforça o conceito de "aprendizagem dialógica". A quinta e última tendência apresentada pelo autor, traz a "escola como comunidades de aprendizagens". Perguntamo-nos, pois, e o professor universitário diante das tendências apresentadas por Imbernóm, como fica? O mesmo só terá sucesso se tiver sua prática pautada no ensino, na pesquisa e na extensão, reforçando a fala de Fernandes e Grillo (2001) adotando nova postura.

Diante de tantas questões, não basta ter conhecimento, ser ativo, mediador, pesquisador, o professor ainda precisa lidar com as carências dos alunos, com as transformações sociais, com os conflitos, com a pluralidade cultural, com a subjetividade coletiva, com o sujeito coletivo, com novos paradigmas. De acordo com Arruda (2008, p. 42), "é certo que mudar o paradigma provoca uma profunda perturbação das consciências e das mentalidades das profissões. Mas é justamente quando o olhar sobre o mundo novo começa a mudar".

A importância e necessidade de programas de formação inicial e continuada dos professores nas universidades é uma premissa do trabalho voltado à transformação social, pois as transformações das práticas docentes só se efetivarão se o professor ampliar sua consciência sobre sua própria prática - a da sala de aula e a da universidade como um todo.

A busca de um novo paradigma demanda uma revisão da visão de mundo de sociedade e de homem [...] a grande contribuição desse movimento prende-se à proposição de superação da teoria não linear e a busca da conexão entre o domínio material e o domínio social. (BEHENS, 2008, p. 12-13) 
Trata-se de atitudes condizentes com uma teoria que busca a emancipação humana, que trata da superação de formas fragmentadas de conhecimentos, de ações fora do contexto social. Trata-se de docentes conscientes da função da Educação, não sendo meros reprodutores de conhecimentos historicamente construídos, mas sim produtores de ideias, com foco na transformação social, como sujeitos sociais, produtores e produtos desta história.

Diante deste processo de quebra de paradigmas da prática educativa no ensino superior, referindo a prática do professor no contexto de compartilhamento de saberes, Anastasiou (2004, p. 32) alega que “o papel do professor será, então, de desafiar, estimular, ajudar os alunos na construção de uma relação com o objeto de aprendizagem que, em algum nível, atenda as necessidades deles, auxiliando-os a tomar consciência das necessidades socialmente existentes numa formação universitária”.

Tratando desses desafios da realidade das universidades e seus professores, Morosini (2001, p. 15) traz questionamentos frente a este contexto, como: “Quem é o docente universitário? Ele está preparado para acompanhar as mudanças do terceiro milênio? O docente está preparado didaticamente para o exercício acadêmico?". Estas perguntas suscitam outros questionamentos referentes à formação dos professores, principalmente pensando em propostas diferenciadas de ensino, como é o caso de muitas universidades, usufruindo das possibilidades de gestão atribuídas em lei.

Ao tratar da legislação referente ao professor universitário, traz-se a LDB, de 1996, que Morosini (2001) comenta:

A principal característica dessa legislação sobre quem é o professor universitário, no âmbito de sua formação didática, é o silêncio. Enquanto nos outros níveis de ensino o professor é bem identificado, no ensino superior parte-se do princípio de que sua competência advém do domínio da área de conhecimento, na qual atua [...] Na base da LDB, fica manifesto que o docente universitário deve ter competência técnica compreendida como domínio da área de conhecimento [...] Entretanto, no plano da formação didática, a LDB se abstém. Em outros atos normativos, embora a formação didática não seja especificada de forma direta, de forma indireta ela o é. Entre esses, um dos mais importantes é o decreto 2.026, de 20 de outubro de 1996, que define o sistema de avaliação do sistema de educação brasileiro [...] o docente passa a ter 
avaliado o seu desempenho, inclusive o didático. (MOROSINI, 2001. p. 17, 18,19)

Ao analisar o texto da LDB na interpretação de Morosini, percebe-se que o mesmo não trata diretamente sobre a formação continuada dos professores mas, ao mesmo tempo, indiretamente a menciona quando trata da avaliação dos processos que direcionam a forma de trabalho deste professor. Mais uma vez, percebe-se a dicotomia entre teoria e prática e ainda a inexistência de uma práxis pedagógica.

Segundo Freire (1996, p. 29), o educador "pesquisa para constatar, constatando, intervenho, intervindo educo e me educo". Reconhece, assim, a educação do mediador voltado às dificuldades de sua prática como também às estratégias para resolvê-las. Quando se fala em mediador, compreende-se numa perspectiva histórico-crítica, em considerar os contextos, em considerar a interdisciplinaridade e o processo de transformação social.

Tratar de formação de professores do ensino superior numa proposta diferenciada de ensino, numa perspectiva histórico-crítica, exige compreender que a produção referese ao conhecimento, às ideias não materiais, exige considerar que "a natureza humana não é dada ao homem, mas é produzida por ele sobre a base da natureza biofísica. Consequentemente, o trabalho educativo é $\mathrm{O}$ ato de produzir, direta e intencionalmente", de acordo com Saviani (1995, p. 11). O autor completa que a educação, em uma visão histórico-crítica, implica em

a- Identificação das formas mais desenvolvidas em que se expressa o saber objetivo produzido historicamente, reconhecendo as condições de sua produção e compreendendo as suas principais manifestações bem como as tendências atuais de transformação;

b- Conversão do saber objetivo em saber escolar de modo a torná-lo assimilável pelos alunos no espaço e tempo escolares;

c- Provimento dos meios necessários para que os alunos não apenas assimilem o saber objetivo enquanto resultado, mas apreendam o processo de sua produção bem como as tendências de sua transformação. (SAVIANI, 1995, p. 15) 
Diante do exposto, o reconhecimento de si, como sujeito produto e produtor da história, exige a consideração do contexto histórico, bem como a aplicabilidade dos conhecimentos desenvolvidos em aula, no dia a dia, transformando e sendo transformado por este contexto, reconhecendo sua função social.

Imbernón (2000) trata de um exercício de análise mais ampla e profunda, considerando o que obtivemos no passado, o que soubemos construir no presente, o que podemos projetar para o futuro, pois o professor encontra-se inserido num contexto repleto de complexidades, de espaços educativos, de diferentes sujeitos históricos, de transformações constantes, de verdades múltiplas, de culturas diversas, que devem ser encaradas como possibilidades e não como problemas.

A função de professor requer pensar em quanto a conectividade está presente em nossas vidas; em quanto as consequências podem ser sutis ou agressivas, mas inevitáveis; em quanto nossas ações geram possibilidades; em quanto poder temos com a criatividade; e em quanto temos a aprender com as situações da natureza.

A instituição de ensino superior, no que se refere à formação de seus docentes, tem muitos desafios a enfrentar. Esta proposta representa a efetividade de uma educação voltada ao desenvolvimento de pessoas pensantes, direcionando suas atribuições profissionais e pessoais rumo ao desenvolvimento social. Segundo Zabalza (2004),

[...] esses grandes desafios para a universidade refletem, se os olharmos com mentalidade positiva, o bom conceito que a sociedade tem dessa instituição e a forte confiança em sua capacidade de influência no desenvolvimento social, cultural e científico dos países. (ZABALZA, 2004, p. 20)

Quando se percebem desafios, reconhecem-se contextos, percebem-se carências, isso é uma demonstração de que o processo não é compreendido como acabado, mas em construção. Quando a instituição de ensino superior, bem como seus professores, se coloca frente a frente com o contexto social, representa uma ação voltada à reflexão, à análise de novas alternativas, de criação de novas ideias, direcionando esforços a uma 
práxis de transformação social e não de reprodução de conhecimento enraizados e fragmentados.

Requer-se principalmente, segundo Anastasiou (2004, p. 54), "a necessidade de profissionalização continuada [...] a alteração da lógica do conhecimento [...] a reorganização do tempo e das ações discentes e docentes [...] a discussão e o aprofundamento vertical [...] o estudo das conexões, as relações [...]" compreendendo que alterar uma estrutura curricular não é algo simples, exige esforço e superação dos diversos desafios inerentes a mudanças e enfrentamento de incertezas.

Ao considerar as mudanças, é preciso admitir que toda mudança exige suporte em diferentes níveis, que, segundo Anastasiou (2004), são de caráter técnico, tratando do saber fazer, exigindo possibilidade de troca, clima de abertura, prática do feedback. E exige olhar na perspectiva cultural, pois as mudanças afetam pela forma que são vistas, sentidas. E também numa perspectiva política, pois envolve o coletivo docente, $\mathrm{o}$ financeiro, além das características pós-modernas, que tratam das incertezas.

Como já citado anteriormente, com o advento de uma sociedade cada vez mais dinâmica e aberta, e a necessidade de sujeitos mais ativos, foi necessário um novo saber pedagógico para enfrentar a problemática educativa. Se de um lado a Pedagogia, como curso, enfrentou problemas na definição de seu papel, e se era negada aos professores a possibilidade de desenvolvimento para além do capital, o próprio contexto histórico e social, como também tecnológico, tratou de definir outra necessidade muito mais abrangente que a de trabalhar conteúdos previamente delimitados e idealizados, para então considerar os contextos históricos, sociais, culturais, espaços geográficos e tecnológicos para uma visão além do capital, mas para transformação social.

Com base nos questionamentos até aqui apresentados, ao se falar em Educação, fala-se em história, sobretudo em transformação social com base no compartilhamento de saberes, de contextos, fazendo menção à relevância da ciência, na compreensão dos processos de educação, da articulação entre teoria e prática, na relevância do conhecimento científico. Lungarzo (1991, p. 9) alega que "todas as pessoas conhecem certos fatos mesmo sem ter estudado ciência", baseando-se no senso comum. Já um cientista detalharia as explicações, buscando conhecimentos mais exatos, mais precisos, com bases sólidas, justificativas claras e exatas. A grande diferença entre conhecimento 
do senso comum e conhecimento científico está relacionada à maneira de conhecer e justificar o conhecimento, sendo o conhecimento, submetido a uma série de testes, análises, controles que garantam obter informações verdadeiras e justificadas.

O conhecimento científico é crítico, é organizado e metódico, enquanto o senso comum é composto por conhecimentos baseados na tradição e na experiência. $O$ cientista organiza seu conhecimento de maneira ordenada, em consonância com certos padrões de pesquisa, certa noção de ordem. A Ciência, como teoria e como conhecimento, "mantém uma relação muito estreita e a tarefa do cientista exige uma interação entre as duas", completa Lungarzo (1991, p.16).

De acordo com Demo (1999, p. 17-18), "a educação não pode fugir do aprimoramento científico [...] não podendo viver à sombra das outras ciências sociais". Tratando este projeto de pesquisa de formação de professores, o autor completa que “ao educador cabe educar a ciência, não desfazê-la, ignorá-la ou temê-la [...] trata-se de fundamentar a necessidade metodológica [...] sob o nome de pedagogia ou ciências da educação". Desta forma, considerar o contexto social, as necessidades e os desafios, e tornar a educação um espaço de trocas, de reflexões, de produção de ideias, é uma forma de fundamentar a necessidade metodológica. Muito se questiona se a educação seria a transmissão de conhecimentos de geração em geração, ou a consciência de construção de conhecimentos e da interferência no contexto em que se está inserido, possibilitando assim a transformação social, sendo esta a premissa da educação, numa perspectiva histórico-crítica, considerando o sujeito como ser construído historicamente e, ao mesmo tempo, construtor desta mesma história. Consideremos que a Educação, quando alcança o objetivo de pensar a transformação social, necessita de sujeitos preparados e abertos para agir em prol desta transformação, como também abertos para se transformarem. A educação é um caminho para tal, desde que supere a produção para além do capital.

Se compreendermos a pedagogia como espaço de pesquisa na contemporaneidade, Bagno (2009, p. 14) enfatiza que o processo da pesquisa consiste na busca do conhecimento a partir de fontes diversificadas, analisadas sob diferentes aspectos, tanto para aprender quanto para ampliar o conhecimento. Ainda de acordo com o autor "tudo isso junto cria um verdadeiro labirinto onde é muito fácil se perder, a 
menos que tenha um bom fio de Ariadne para se orientar. E esta é mesmo a palavrachave: orientação".

Destacando o valor da pesquisa e relacionando ao nosso lócus de investigação, Dias Sobrinho (2005, p. 15) diz que a universidade "não é uma realidade acabada e pronta [...] é uma instituição social de caráter essencialmente pedagógico". Desta forma, conhecê-la, apreendê-la faz toda a diferença na prática pedagógica, uma vez que, de acordo com o mesmo autor, "dizer que a função pedagógica tem sentido social e público é também afirmar que ela se movimenta nas contradições, divergências e disputas do cotidiano". Frente a esta discussão, considerar uma leitura de realidades, de contextos, de alunos, de homens, nos faz parar e agir, resgatar e aprimorar nossos saberes e práticas, visando uma educação voltada para a emancipação humana.

Destaca-se aí a pesquisa. Segundo as premissas de Bagno (2009), o educador deve respeitar os saberes que os alunos adquiriram em sua história de vida, estimulando-os a sua superação por meio do despertar da curiosidade que os instiga à imaginação, à observação, a questionamentos, alcançando uma explicação epistemológica. Para o autor,

[...] ensinar a aprender, então, é não apenas mostrar os caminhos, mas também orientar o aluno para que desenvolva um olhar crítico que lhe permita desviar-se das 'bombas' e reconhecer, em meio ao labirinto, as trilhas que conduzem ás verdadeiras fontes de informação e conhecimento. (BAGNO, 2009, p. 15)

A prática de pesquisa na Educação, bem como o próprio termo tem sido utilizado com certo abuso e fora do seu sentido real. Mesmo sendo utilizada nas escolas de modo geral, sendo encarada pelos professores e alunos como pesquisa em meios diversos, como jornais, livros, revistas, não representa seu verdadeiro conceito. Não se renega aí que esta ação possa contribuir para o desenvolvimento da curiosidade. No entanto, de acordo com Ludke (1986, p. 1), “para realizar uma pesquisa é preciso promover o confronto entre os dados, as evidências, as informações coletadas sobre determinado assunto e o conhecimento teórico acumulado a respeito dele”. 
Outro fator preponderante diante da pesquisa na educação é a necessidade de reflexão sobre a práxis educativa para evitar a reprodução alienada, promovendo possibilidades para o aluno produzir conhecimentos, buscando a superação da fragmentação curricular. Desta forma, pensar sobre formação de professores envolve perguntar, observar, compartilhar, visando à construção de novos conhecimentos, com foco na emancipação humana e transformação social.

A práxis, conforme Vasquez (1977, p. 5) vai além do significado de prática, como prática humana, destaca que práxis “é uma categoria central da filosofia que se concebe ela mesma não só como interpretação do mundo, mas também como guia de sua transformação. Tal filosofia não é outra senão o marxismo". Tratar da formação de professores numa proposta diferenciada de ensino requer reconhecer a práxis pedagógica voltada para a transformação social, para a criação de novas alternativas de ensino, pesquisa e extensão, tornando assim uma possibilidade de emancipação humana, não somente como uma proposta diferenciada para atender as questões financeiras, mas realmente ser um diferencial na formação de professores.

Voltando à linha de pensamento de Bagno, constata-se o resultado da pesquisa produto da interpretação do aluno, ser histórico, diante das diferentes fontes obtidas para a pesquisa. É perceptível a necessidade de preparar os alunos para irem além - além do que falam os livros, além das possibilidades que lhes são oferecidas, portanto, o professor deve preparar seus alunos para uma constante busca do conhecimento.

Os protagonistas da ação - professor e aluno - devem participar simultaneamente de todo o processo de Educação, no qual juntos ensinam e também aprendem. É essencial que tanto o aluno quanto o professor se utilizem da pesquisa como prática cotidiana, mas para a obtenção do resultado é indispensável que as técnicas de pesquisa sejam discutidas e preparadas, para que o processo seja consciente. 


\section{Considerações finais}

Assim como a universidade é considerada como um espaço de tomada de decisões formativas, conforme afirma Zabalza (2004), então a prática docente no ensino superior precisa rever os paradigmas do processo ensino-aprendizagem, redimensionando o conceito de ensinar e de aprender, de acordo com Fernandes e Grillo (2001), em que se faz necessário refletir, analisar, comparar, criticar, justificar, argumentar, inferir conclusões contextualizadas. E esta ação é divergente de instruir, mostrar, guiar, comunicar conhecimentos.

O espaço da universidade nos remete à pedagogia universitária, compreendida por Pimenta (2011) como uma forma de trabalho que pressupõe professores capazes de considerar contextos históricos, sociais, culturais e organizacionais, que articulem a teoria, a reflexão e a prática. Uma nova ação por parte dos professores requer um processo de formação que supere o trabalho isolado; configuram-se novos modos de planejar atividades a serem desenvolvidas pelos acadêmicos de forma autônoma, uma nova organização de recursos e espaços. Exige pesquisa e produção de conhecimento, pois o professor que não pesquisa não consegue incentivar os alunos a pesquisarem, nem consegue estabelecer processos de parceira, como coparticipantes de um mesmo processo, estabelecendo uma troca de saberes entre professores e alunos, numa visão interdisciplinar.

Por sua vez, Pimenta (2011) fala de uma nova cultura acadêmica, que mude a postura diante do saber, que problematize as informações e garanta a formação do cidadão e profissional, que possibilite o pensamento autônomo, mobilize ações interdisciplinares, estruturas globalizantes, que problematizem conhecimentos historicamente construídos, trazendo resultados na construção da sociedade e das novas demandas a que esta se coloca, mas também salienta que esta estruturação é um grande desafio.

No que condiz com essa nova cultura acadêmica, voltada ao contexto social, histórico, cultural, infere em pesquisa diante do processo de construção do conhecimento, tornando este espaço, possível de criticidade, de manifestações humanas, de transformação social. Tratar a pedagogia enquanto espaço de pesquisa, envolve 
abordagens interdisciplinares, uma vez que através da pesquisa, links são estabelecidos entre contextos, entre problemas e entre possibilidades de emancipação do sujeito histórico.

Finalizando, Santomé (1998) sustenta que a interdisciplinaridade é um objetivo nunca completamente alcançado e por isso deve ser permanentemente buscado. Não é uma proposta teórica, mas, sobretudo uma prática. O Parecer $n^{\circ}$ 2475/06, que normatiza a proposta em questão cita que é necessário um conjunto de ações capazes de articular as várias instâncias acadêmicas e administrativas, na perspectiva do enfrentamento possibilitando alternativas para manutenção dos cursos de licenciatura na Universidade, mas na prática ficamos na dependência dos professores e no comprometimento de cada um em desenvolver atividades realmente interdisciplinares, o que se torna uma tarefa difícil, pois não ocorre aquele falado acordo coletivo entre professores, entre alunos e entre alunos e professores.

Certamente, pensar em mudanças requer considerar que toda mudança exige suporte em diferentes níveis, sejam de caráter técnico, cultural ou político, pois envolvem o coletivo docente, o financeiro, além das características pós-modernas, que tratam das incertezas. Fica aqui um adendo frente à realidade da qual estamos falando, uma realidade de contradições sociais, culturais e políticas, ou uma realidade definida e alinhada conforme as premissas dos dominantes? A universidade nunca estará pronta e acabada, os contextos não são estáticos, então a Educação também não pode assim ser. Superar as práticas pedagógicas que tradicionalmente dicotomizam teoria $\mathrm{x}$ prática, pensar $x$ fazer, trabalho $x$ estudo, pesquisa $x$ ensino, resultará em vantagem para todos. Este desafio está a caminho de ser cumprido e à espera de muitos outros. 


\section{Referências}

ANASTASIOU. Léa das Graças Camargos (org.). Processos de ensinagem na universidade: pressupostos para as estratégias de trabalho em aula. Joinville: Univille, 2004.

ARRUDA, Marina P. (RE) significando a mediação social: um medidor de emoções.

Pelotas: Mundial, 2008.

BAGNO, Marcos. Pesquisa na escola: o que é, como se faz. 23. ed, São Paulo: Loyola, 2009.

BEHENS, Marilda A. Paradigma da complexidade: metodologia de projetos / contratos didáticos e portifólios. Petrópolis: RJ: Vozes, 2008.

BRANDÃO, Carlos Rodrigues. O que é educação? São Paulo: Brasiliense, 2001.

CAMBI, Franco. História da pedagogia. São Paulo: Fundação Editora da UNESP (FEU), tradução Álvaro Lorencini, 1999.

DEMO, Pedro. Cidadania tutelada e cidadania assistida. Campinas, SP: Autores Associados, 1999.

DEMO, Pedro. Pesquisa princípios científicos e educativos. São Paulo: Cortez Autores Associados, 1990.

DIAS SOBRINHO, José Dias; BALZAN, Newton Cesar. Avaliação institucional: teoria e experiências. São Paulo: Cortez, 2005.

FERNANDES, Cleoni Maria Barboza; GRILLO, Marlene. Educação superior travessuras e atravessamentos. Canoas: Ed. ULBRA, 2001.

FREIRE, Paulo. Pedagogia da autonomia: saberes necessários à prática educativa. 42. Ed. São Paulo: Paz e Terra, 1996.

IMBERNÓN, Francisco (org.). A educação no século XXI: desafios do futuro imediato.

Tradução Ernani Rosa - 2. Ed., Porto Alegre: Artmed, 2000.

LUDKE, Menga. ANDRÉ, Marli E. D. A. Pesquisa e educação: abordagens qualitativas. São Paulo: EPU, 1986.

LUNGARZO. Carlos, O que é ciência? São Paulo: Editora Brasiliense, 1991.

MAZZETTO, Marcos Tarciso. Competências pedagógicas do professor universitário. São Paulo: Summus, 2003.

MAZZETTO, Marcos Tarciso. Competências pedagógicas do professor universitário. São Paulo: Summus, 2012. 
MOROSINI. Marília Costa (org.), Professor do ensino superior: identidade, docência e formação. Brasília: Plano Editora, 2001.

PIMENTA, Selma Garrido. Pedagogia: ciência da educação? Selma Garrido Pimenta, (Coord.). 6. Ed. São Paulo: Cortez, 2011.

PIMENTA, Selma Garrido. Docência no ensino superior. São Paulo: Cortez, 2003.

PIMENTA, Selma Garrido; ALMEIDA, Maria Isabel de (orgs.). Pedagogia Universitária: caminhos para a formação de professores. Selma Garrido Pimenta, São Paulo: Cortez, 2011.

PIMENTA, Selma Garrido. Pedagogia: ciência da educação? 6. Ed. São Paulo: Cortez, 2011.

SANTOMÉ, Jurjo Torres. Globalização e interdisciplinaridade: o currículo integrado. Porto Alegre: Editora Artes Médicas Sul LTDA, 1998.

SAVIANI, Demerval. A pedagogia no Brasil: história e teoria. Campinas, CP: Autores Associados, 2008.

SAVIANI, Demerval. Escola e democracia: teoria as educação, curvatura da vara, onze teses sobre educação e política. Campinas: Autores Associados, 1997.

SAVIANI, Demerval. História das idéias pedagógicas no Brasil. $2^{\mathrm{a}}$ ed. Campinas, São Paulo: Autores Associados, 2008.

SAVIANI, Demerval. Pedagogia histórico-crítica: primeiras aproximações. Campinas SP: Autores Associados, 1995.

ZABALZA, Miguel A. O ensino universitário: seu cenário e seus protagonistas. Porto Alegre: Artmed, 2004. 